\title{
Laparoscopic Approach to a Case of Appendicular Schwannoma
}

\author{
Suk Won Suh, Joong Min Park, Yoo Shin Choi, Sung Jae Cha, In Taik Chang, Beom Gyu Kim \\ Department of Surgery, Chung-Ang University College of Medicine, Seoul, Korea
}

Appendicular schwannoma is a rare tumor originating from Schwann's cells in the Auerbach plexus. The preoperative diagnosis is difficult because the clinical features are nonspecific, and it is mostly found accidentally via a radiologic image as a tumor, mimicking malignancy. We report a case of an appendicular schwannoma coexisting with an adenocarcinoma in the lung. A laparoscopic appendectomy was done with a clear resection margin, and the immunohistochemical staining showed positive S-100 protein, which confirmed the schwannoma. The patient also underwent a left upper lobectomy of the lung. The patient has been free of recurrence for the 6 months since the operation. The laparoscopic approach could be available for treatment of an appendicular schwannoma, thus avoiding an unnecessary laparotomy.

Keywords: Schwannoma; Appendix; Appendectomy; Laparoscopic surgery

\section{INTRODUCTION}

Gastrointestinal autonomic nerve tumors (GANTs) were first described by Herrera et al. [1] in 1984. They have recently been distinguished from each other, leiomyoma, leiomyosarcoma, leiomyoblastoma, schwannoma, and gastrointestinal stromal tumor (GIST), on the basis of the tumor cell differentiation revealed by immunohistochemical studies. The term GIST, a subgroup of GANTs, has recently been applied to mesenchymal tumors with nonspecific ultrastructual findings [2]. Schwannomas are tumors derived from Schwann cells in the Auerbach plexus which form a neural sheath, accounting for 2-6 of all neoplasms of the gastrointestinal tract [3]. It is well established that schwannomas appear more frequently in the stomach and the small bowel; those with a location in the co-

Received: January 21, 2010 Accepted: May 26, 2010

Correspondence to: Beom Gyu Kim, M.D.

Department of Surgery, Chung-Ang University Hospital,

224-1 Heukseok-dong, Dongjak-gu, Seoul 156-755, Korea

Tel: +82-2-6299-1545, Fax: +82-2-824-7869

E-mail: kimbg0526@ paran.com

Poster presentation at the 61th annual meeting of the Korean Surgical Society, 2009.

(C) 2010 The Korean Society of Coloproctology

This is an open-access article distributed under the terms of the Creative Commons Attribution NonCommercial License (http://creativecommons.org/licenses/by-nc/3.0) which permits unrestricted noncommercial use, distribution, and reproduction in any medium, provided the original work is properly cited. lon are rare $[4,5]$. We report an unusual case of an appendicular schwannoma arising in the tip of the appendix. A review of the previous literature is also presented.

\section{CASE REPORT}

A 68-year-old man presenting with intermittent cough and sputum for 1 month without any abdominal symptoms was admitted to our hospital. He had no remarkable past medical history. The vital signs were all in the normal range. The laboratory findings were within normal limits, including a negative sputum culture (gram stain and AFB culture). There was a consolidation with the opacity of ground glass in the left upper lobe lingular division on the chest computed tomography (CT), suggesting pneumonia or a malignancy such as a bronchioloalveolar carcinoma (BAC) or a lymphoma. The percutaneous needle aspiration biopsy confirmed an adenocarcinoma with a moderately-differentiated pathology. Further evaluations were done for cancer stage work-up, and the abdomino-pelvic CT showed about a $1.4 \mathrm{~cm}$, well-enhanced nodule on the tip of the appendix, suggesting carcinoid tumor (Fig. 1). Positron emission tomography (PET) CT also showed a lesion in the appendix that could not be ruled out for metastasis (Fig. 2).

The patient underwent a left upper lobectomy of the lung and a laparoscopic appendectomy (Fig. 3). During the operation, a frozen biopsy was done that showed a neurogenic stromal tumor with a clear resection margin. The appendix tumor 

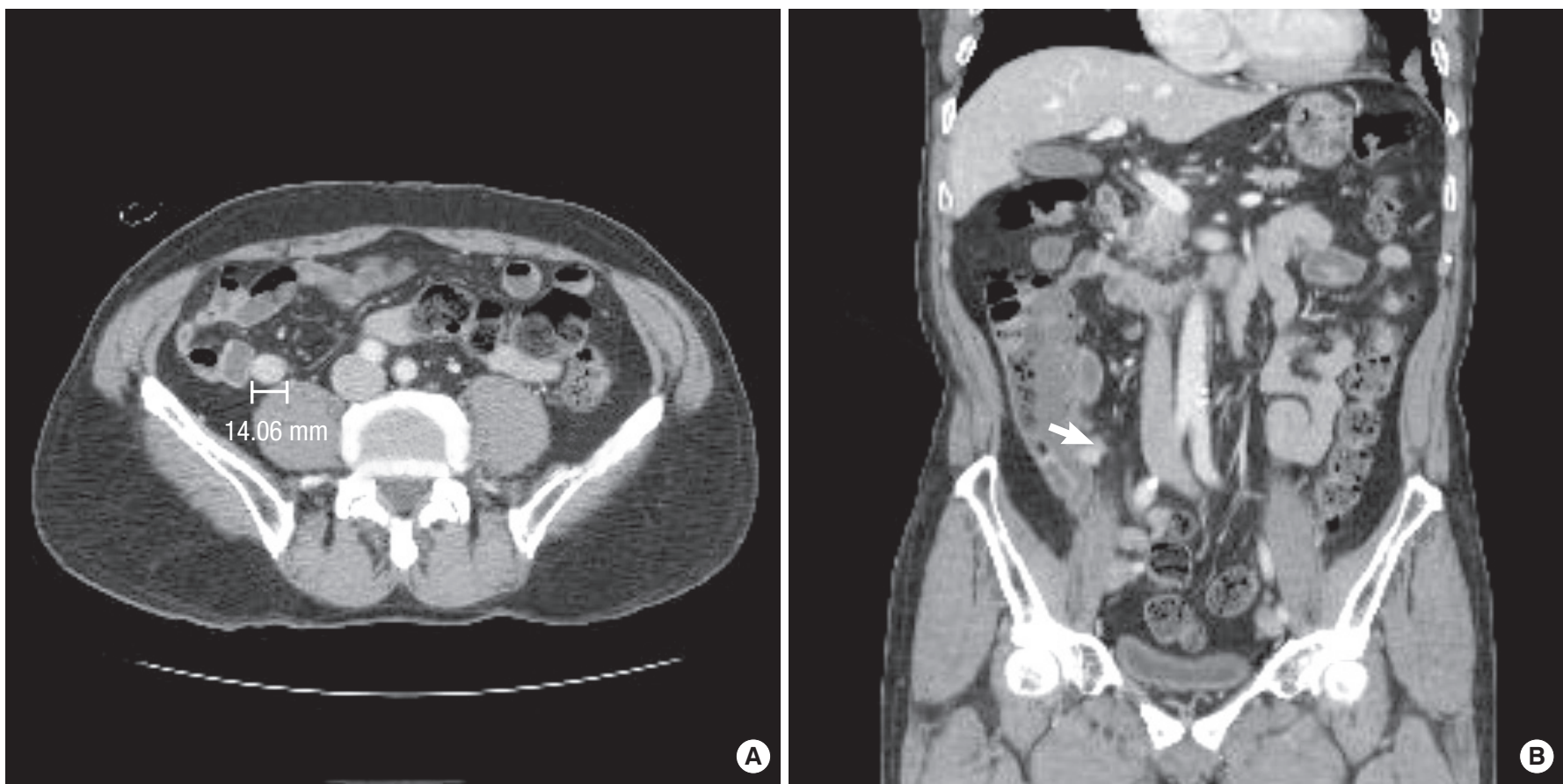

Fig. 1. Axial (A) and coronal (B) images of abdomino-pelvic CT scans show a well-enhanced nodule of about $1.4 \times 1.0 \mathrm{~cm}^{2}$ in the tip of the appendix (arrow).

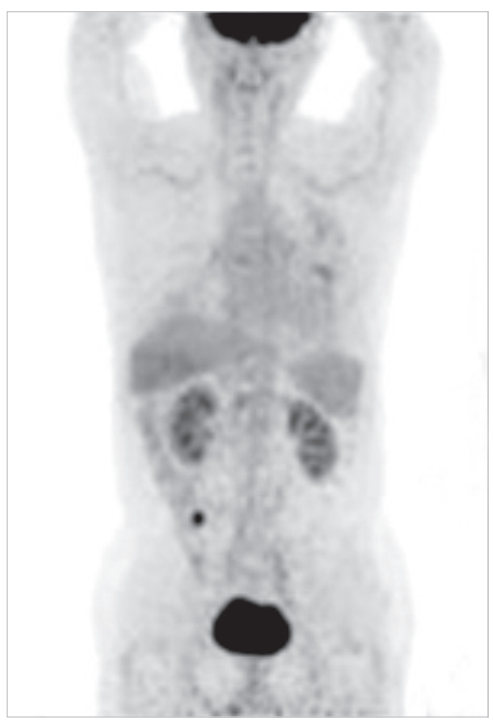

Fig. 2. PET CT shows a hypermetabolic lesion in the appendix nodule; a malignancy cannot be ruled out.

was $2.3 \times 1.8 \times 1.1 \mathrm{~cm}$ in size with a $2.3 \mathrm{~cm}$ resection margin, suggestive of an appendix stromal tumor (favoring a neurogenic tumor) (Fig. 4). The immunohistochemical staining showed positive S-100 protein, consistent with the diagnosis of a schwannoma (Fig. 5). The patient was followed for 6 months later, and no evidence of specific complications or recurrence on abdomen was noted, but cancer recurred in the other lung, so the patient underwent palliative chemotherapy.

\section{DISCUSSION}

Schwannomas account for $1 \%$ of all malignant gastrointestinal tumors. They are mainly benign neurogenic tumors arising from the sheath of the peripheral nerves, but they may undergo malignant changes if left untreated $[6,7]$. There is no difference in the rates of incidence in men and women, and a median age of presentation is 65 years of age. These tumors frequently occur in the head and neck, the spinal cord, and the extremities, but they are seldom found in the abdomen. In the gastrointestinal tract, schwannomas are mostly found in the stomach, but reports of their being present in the colon and rectum are rare, and most grow outside the lumen contralateral to the mesenteric attachment $[3,4]$.

Although neurogenic tumors usually grow very slowly and the symptoms are vague and nonspecific, common symptoms are abdominal pain, apalpable mass, and hemorrhage; however, intestinal obstruction is rare $[3,5,8]$. In the small intestine, hemorrhage is the most frequent symptom because when the tumor grows, abundant blood vessels in the submucosal tumor become exposed on the surface of mucosa and may easily be injured [9]. Approximately 30-50\% of appendicular tumors show clinical symptoms and signs similar to those of appendicitis, and this rate is higher for carcinoid tumors than it is for other tumors. However, the majority of patients, as our patient, have nonspecific symptoms, which makes preoperative diagnosis very difficult; thus, the tumor is often found in- 
cidentally [10-12].

For the diagnosis of a schwannoma, conventional imaging modalities, including CT, ultrasonography, barium enema, magnetic resonance imaging, and endoscopy, are useful for tumor localization [4-7]. Sometimes, angiography of the mesenteric vessels can show hypervascular tumor vessels. Also, blood loss scintigraphy, which can detect minor hemorrhage, has been reported to enable the diagnosis of jejunal tumors [8]. However, we could not distinguish benign from malignant stromal tumors by using radiologic images alone. In our case, we found the appendicular tumor suggesting a carcinoid tumor by using an abdomino-pelvic CT, but PET CT could not rule out the possibility of malignancy, so surgical exploration was performed.

One study showed that patients treated for an appendicular neoplasm had a higher rate of associated cancer than the normal population, especially synchronous colon carcinomas. Thus, the authors of that study recommended a colonoscopic examination in patients with incidentally-discovered appendicular

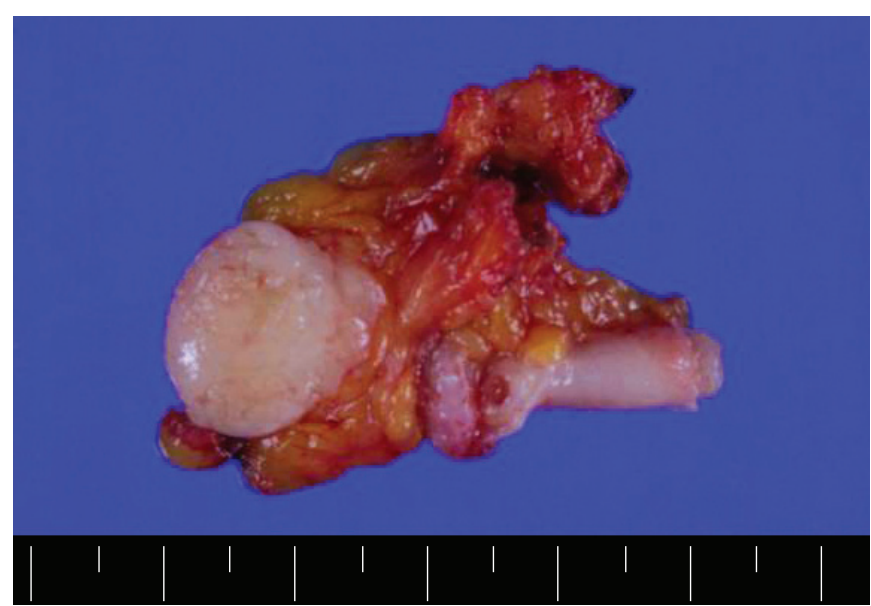

Fig. 4. Macroscopic view of the resected specimen showing a wellencapsulated solid tumor measuring $2.3 \times 1.8 \times 1.1 \mathrm{~cm}^{3}$ in size. The cut surface is a yellowish-white color and fleshy without any areas of necrosis or hemorrhage.
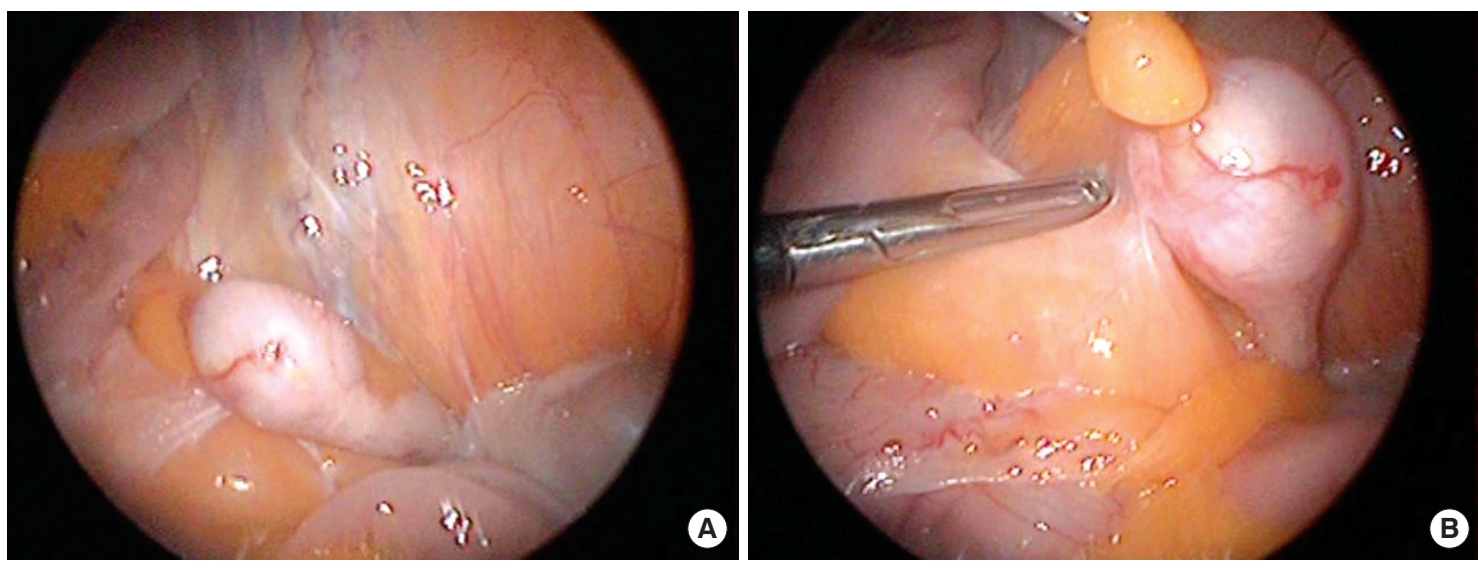

Fig. 3. Laparoscopic view during surgery. A smooth, yellowishwhite tumor in the tip of the appendix was resected by using a laparoscopic approach.
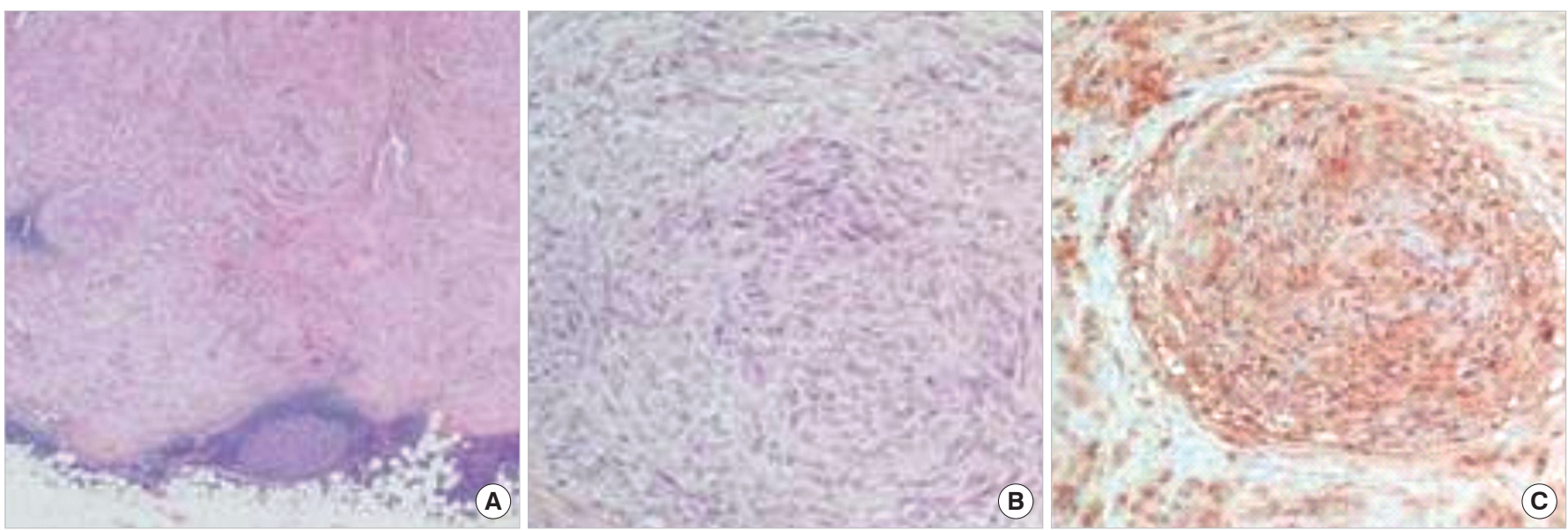

Fig. 5. Microscopic findings of schwannoma. (A) The appendiceal lumen is filled with cellular spindle cell proliferation in the background of the remaining lymphoid tissue $(\mathrm{H} \& \mathrm{E}, \times 40)$. (B) The tumor is composed of elongated Schwann cells $(\mathrm{H} \& \mathrm{E}, \times 200)$. (C) Immunohistochemical staining for the S-100 protein identifies the cells $(S-100, \times 200)$. 
tumors [11].

Immunohistological studies of GANTs play a key role in the differentiating a schwannoma from other stromal tumors which have high potential of malignancy. S-100 protein, a nervous tissue-specific protein, and non-specific enolase, a molecular marker of peripheral and central neuroendocrine cells, aree useful for indicating schwannoma cell line tumors $[2,3,6,7$, 13]. Our patient also had positive $S-100$ protein, but showed negative for CD 34, which is usually up to $80 \%$ positive for gastrointestinal stromal tumors other than schwannomas.

A complete surgical resection is the treatment of choice while chemotherapy or radiotherapy is not effective. These tumors have a low rate of recurrence. The surgical approaches depend on the tumor size and on the histologic features that mainly determine the prognosis, so preoperative imaging tests are very important in the selection of patients for surgical resection. However, in the case of malignant neurinomas, the prognosis is poor because hematogenous metastasis to the lung and the liver frequently occur $[2,3,6,7,13]$. Because of its low incidence, the optimal treatment for a malignant schwannoma has not been not fully established, but like other soft tissue sarcomas, only a complete surgical resection can provide a chance for cure. The surgical margin has been advocated to be the most important prognostic factor, so every effort should be made to achieve a tumor-free surgical margin without unnecessary sacrifice of nerves [14].

The indications for a laparoscopic approach to the resection of tumors have not yet been established definitively. One report indicates that laparoscopy does not increase the risk of local recurrence or metastasis compared with the open surgery, but another shows an increased rate of peritoneal seeding and abdominal wall metastasis after laparoscopic resection [11].

It has been generally accepted that appendicular carcinoids can be treated by using a simple appendectomy with a clear resection margin. However, if they are larger than $2 \mathrm{~cm}$ in size or if the base of the appendix or the mesoappendix is involved, general agreement exists that a right hemicolectomy should be performed. Benign appendicular tumors, including mesenchymal tumors without malignant components, are traditionally treated with a complete surgical resection or a limited cecal resection if the resection margin is involved. In the case of malignant lesions, improved survival was seen in patients who underwent a right hemicolectomy compared with patients who underwent an appendectomy alone $[11,12,15,16]$.

The tumor should be assessed intraoperatively, and the treatment should be tailored to each individual patient based on the frozen biopsy results. In our case, the patient received a laparoscopic appendectomy with a free resection margin, favoring a neurogenic stromal tumor. Therefore, the laparoscopic approach could be technically challenging even if the tumor is preoperatively suggested to be malignant.

A schwannoma of the appendix is a very rare tumor. It pres- ents without any specific symptoms, so its preoperative diagnosis is difficult. Complete surgical excision is thought to be the best approach and to determine the overall outcome. Laparoscopic surgery, however, with a clear resection margin should be available for treatment of an appendicular schwannoma and should result in a favorable prognosis with recurrence being unusual; thus, an unnecessary laparotomy can be avoided.

\section{CONFLICT OF INTEREST}

No potential conflict of interest relevant to this article was reported.

\section{REFERENCES}

1. Herrera GA, Pinto de Moraes H, Grizzle WE, Han SG. Malignant small bowel neoplasm of enteric plexus derivation (plexosarcoma): light and electron microscopic study confirming the origin of the neoplasm. Dig Dis Sci 1984;29:275-84.

2. Mulchandani MH, Chattopadhyay D, Obafunwa JO, Joypaul VB. Gastrointestinal autonomic nerve tumours: report of a case and review of literature. World J Surg Oncol 2005;3:46.

3. Kang DB, Kim SH, Oh JT, Park WC, Lee JK, Kim HS. Colonic Schwannoma. J Korean Surg Soc 2007;73:183-7.

4. Fotiadis CI, Kouerinis IA, Papandreou I, Zografos GC, Agapitos G. Sigmoid schwannoma: a rare case. World J Gastroenterol 2005; 11:5079-81.

5. Min YW, Kim YH, Yun HS, Kil JS, Kim YC, Yun SH, et al. A case of benign schwannoma in the ascending colon. Korean J Gastroenterol 2007;50:398-401.

6. Miettinen M, Sobin LH. Gastrointestinal stromal tumors in the appendix: a clinicopathologic and immunohistochemical study of four cases. Am J Surg Pathol 2001;25:1433-7.

7. Braumann C, Guenther N, Menenakos C, Junghans T. Schwannoma of the colon mimicking carcinoma: a case report and literature review. Int J Colorectal Dis 2007;22:1547-8.

8. Gupta A, Rattan KN, Gupta A, Banerjee D. Giant appendicu lar schwannoma in a child. Indian J Pathol Microbiol 2009;52: 281-2.

9. Nagai T, Fujiyoshi K, Takahashi K, Torishima R, Nakashima H, Uchida A, et al. Ileal schwannoma in which blood loss scintigraphy was useful for diagnosis. Intern Med 2003;42:1178-82.

10. Jung SH, Park WK, Kim JW, Chang JC, jang HW, Jung YJ, et al. Schwannoma of the appendix: a case report. J Korean Radiol Soc 2006;54:127-30.

11. Bucher P, Mathe Z, Demirag A, Morel P. Appendix tumors in the era of laparoscopic appendectomy. Surg Endosc 2004;18:1063-6.

12. Murphy EM, Farquharson SM, Moran BJ. Management of an unexpected appendiceal neoplasm. Br J Surg 2006;93:783-92.

13. Hwang HC, Kang SH, Lee DS, Bae YK. Appendiceal Schwannoma. J Korean Surg Soc 2006;70:73-6.

14. Lee YJ, Moon H, Park ST, Ha WS, Choi SG, Hong SC, et al. Ma- 


\section{Coloproctology suk Won Suh, et al.}

lignant peripheral nerve sheath tumor arising from the colon in a newborn: report of a case and review of the literatures. J Pediatr Surg 2006;41:e19-22.

15. Fornaro R, Frascio M, Sticchi C, De Salvo L, Stabilini C, Mandolfino $\mathrm{F}$, et al. Appendectomy or right hemicolectomy in the treat- ment of appendiceal carcinoid tumors? Tumori 2007;93:587-90.

16. Iwuagwu OC, Jameel JK, Drew PJ, Hartley JE, Monson JR. Primary carcinoma of the appendix - Hull series. Dig Surg 2005;22: 163-7. 